\title{
TUMOR ODONTOGÊNICO CERATOCÍSTICO: DO DIAGNÓSTICO AO TRATAMENTO
}

\section{ARTIGO DE REVISÃO}

ANNUNCIAÇÃO, Andressa Vitória Tavares Pereira da ${ }^{1}$

ANNUNCIAÇÃO, Andressa Vitória Tavares Pereira da. Tumor Odontogênico Ceratocístico: Do diagnóstico ao tratamento. Revista Científica Multidisciplinar Núcleo do Conhecimento. Ano 05, Ed. 09, Vol. 02, pp. 85-90. Setembro de 2020. ISSN: 2448-0959, Link

acesso: https://www.nucleodoconhecimento.com.br/odontologia/tumor-odontogenico

\section{RESUMO}

Os tumores odontogênicos são neoplasias que se desenvolvem na região dos ossos gnáticos, originando-se dos tecidos odontogênicos por proliferação de tecido epitelial, mesenquimal ou de ambos. Dentre eles, podemos citar o ceratocisto odontogênico que possui características próprias e totalmente diferenciadas de qualquer outra patologia bucal apresentando um desafio para diagnóstico ao profissional. O objetivo deste trabalho é realizar uma revisão de literatura sobre o Ceratocisto Odontogênico e abordar características clínicas e radiográficas associadas a essa patologia, assim como a abordagem terapêutica da mesma.

Palavras-chave: tumor, odontogênico, patologia, neoplasias.

\section{INTRODUÇÃO}

Os primeiros casos clínicos apresentados nos pacientes foram descritos como um colesteatoma (apresentação de crescimento progressivo do epitélio escamoso queratinizado). Em 1992 foi chamado de cisto primordial ou ceratocisto odontogênico. A última classificação da Organização Mundial de Saúde (OMS) dos tumores

\footnotetext{
${ }^{1}$ Graduada em Odontologia pela UNBF.
} 
odontogênicos, denominou o ceratocisto odontogênico como tumor odontogênico ceratocístico, com critério na presença de alterações genéticas, moleculares, que estariam também presentes em algumas neoplasias.

Mesmo ainda possuindo etiologia desconhecida, há uma concordância geral de que o ceratocisto odontogênico surge a partir dos restos celulares da lâmina dental, no período de desenvolvimento da odontogênese, descartando a hipótese de que sua formação seja por meio do epitélio bucal. Essa patologia apresenta um mecanismo de crescimento e comportamento biológico diferentes das patologias que são mais comuns de serem encontradas na rotina clínica diária devido ao seu comportamento agressivo e a alta taxa de casos recidivantes. É importante citar que há chance elevada de causar morbidade quando não diagnosticado precocemente. Possui natureza benigna de evolução lenta e comportamento clínico agressivo e assintomático com predileção pela região posterior e ramo ascendente da mandíbula, estando na maioria dos casos associados a um dente incluso. Há relatos de casos que a lesão foi apresentada na maxila, mas não é algo comum. Os sinais radiográficos são apenas característicos da lesão, porém o exame histopatológico deve ser feito para conclusão do diagnóstico para descartar qualquer possibilidade de diagnóstico diferencial com outras patologias.

\section{REVISÃO DE LITERATURA}

O CO é uma forma distinta de patologia odontogênica de desenvolvimento que necessita de considerações especiais por causa do seu comportamento clínico, aspectos histopatológicos específicos e sua alta taxa de recidiva. É apresentado em pacientes de ampla faixa etária e possui predileção pelo sexo masculino assim como a região dos molares inferiores (principalmente em regiões de terceiros molares) e no ramo da mandíbula.

\subsection{SINAIS E SINTOMAS}

Os sinais e sintomas geralmente se fazem ausentes, e sua descoberta só é realizada através de exames radiográficos de rotina. Em casos de lesões mais extensas, 
identifica-se tumefação, drenagem ou dor associada e local, aumento de volume de tecidos moles e tecido ósseo, parestesia e mobilidade de dentes envolvidos pela lesão, caracterizando a lesão com crescimento lento e deslocamento de estruturas dentárias pelo aumento da perda de suporte ósseo.

Amorim et al. (2003) apresentaram uma avaliação epidemiológica de 26 casos de cistos diagnosticados como ceratocisto odontogênico e identificaram em sua maioria a presença de lesões em pacientes do sexo masculino, com idades variantes a partir de quarenta anos e de raça branca, localizados, principalmente, na região posterior de mandíbula. Partindo do tempo da evolução das lesões, foi possível observar um desenvolvimento lento, não havendo predominância padrão radiográfico específico. Já nos diagnósticos analisados, não foi identificado na maioria das vezes algo condizente em relação ao diagnóstico histopatológico, mas sim a ameloblastoma, sendo está a principal lesão citada nas hipóteses diagnósticas. (VAROLI et al., 2010)

É de extrema importância que o profissional avalie o paciente quanto à possibilidade de Síndrome de Gorlin-Goltz, visto que a mesma está associada ao surgimento de múltiplos ceratocistos, alterações plantares e palmares e carcinomas nevoides de células basais.

Radiograficamente, tal patologia é vista como uma lesão circular ou ovoide de forma radiolúcida - unilocular ou multilocular - e margens regulares radiopacas, com limites precisos (bem definido e corticalizado). Há ocorrência de reabsorção radicular raramente e está associado a dente incluso de 25 a 40\% dos casos apresentados.

\subsection{TRATAMENTO}

O tratamento do CO é de imenso desafio para os cirurgiões, considerando-se o elevado grau da taxa de recidiva. É levado em consideração a idade do paciente e o tamanho da lesão para a melhor seleção da escolha do tratamento com o intuito de viabilizar a saúde do portador da lesão. A marsupialização pode ser usada como forma de tratamento de primeira instância, visando proteger estruturas importantes e nobres. Numa segunda visão, toda a lesão deverá ser removida. A injeção da solução de 
Carnoy na região do lúmen do cisto também tem sido utilizada para desprender o cisto da parede óssea, facilitando a remoção da lesão e com taxas de recidiva mais baixa. Ela também é feita juntamente com a enucleação e curetagem (GUERRA et al., 2013). Alguns fatores que podem estar associados a esta recorrência são: a presença de cistos satélites que se perdem durante a remoção cirúrgica e/ou cápsula fina e friável, dificultando a enucleação sem que haja fragmentação da lesão. O CO tem prognóstico ruim, independentemente de qual método de tratamento será utilizado na sua remoção, por conta da sua alta taxa de recidiva.

\section{DISCUSSÃO}

Para haver confirmação do diagnóstico de CO é necessária a realização do exame histopatológico (sendo assim, realizado o exame de biópsia), pois a mesma pode ser confundida com outras patologias como: ameloblastoma, tumor odontogênico adenomatoide, cisto dentígero, cisto odontogênico calcificante e fibroma ameloblástico. Sua histopatologia apresenta camada de células basais bem definida e empaliçada e hipercromática, cápsula fina e friável, paraceratina corrugada, parede fibrosa fina e sem infiltrado inflamatório assim como também possui ausência de cristas interpapilares. Há unificação de camada de epitélio escamoso estratificado com cinco a sete camadas de células e, na recorrência da lesão, satélites podem ser vistos na cápsula fibrosa.

Chi et al. (2005) relataram dois casos que apresentaram a ocorrência de lesões no tecido mole do queratocisto intraósseo, identificada como queratocisto odontogênico periférico. Entretanto há uma diferenciação na parte dos diagnósticos com relação a classificação dessa ocorrência na mucosa gengival, na qual uns a consideram como uma variante histológica do cisto gengival, enquanto outros acreditam ser a forma periférica do queratocisto odontogênico. (VAROL et al., 2010)

Forssell et al. (1988) analisaram o pós operatório de 75 pacientes portadores de CO por cinco anos, totalizando $43 \%$ de casos com prognósticos ruins porque os mesmos foram recidivados. Recidivas encontradas nos pacientes portadores da Síndrome de Gorlin,o que passa a ser exigido um acompanhamento o mais longo possível. 
Através de seu estudo sobre a genética do tumor odontogênico queratocístico, Heikinheimo et al. 20 (2007) verificaram que a presença excessiva de genes pode contribuir para contínuo do tumor odontogênico queratocístico. (VAROLI et al., 2010)

Casos com infecção secundária, com perfuração das corticais, e com aspecto multilocular apresentaram maior chance de ocorrência de recidiva.

\section{CONCLUSÃO}

Atualmente, em decorrência de sua agressividade, potencial de crescimento, natureza neoplásica e alto índice de recorrência, o ceratocisto ou queratocisto odontogênico, é denominado como um tumor odontogênico. (VAROLI et al., 2010)

Em vista de todo conteúdo supracitado, é de suma importância o conhecimento de patologias bucais associadas a origens odontogênicas pelo cirurgião-dentista com o objetivo da elaboração de um correto e precoce diagnóstico para a melhor escolha do tratamento, visando o bem estar do paciente e promovendo saúde para o mesmo. O Ceratocisto Odontogênico requer procedimentos terapêuticos apropriados para o sucesso do tratamento. É indispensável o encaminhamento do paciente para a realização do exame histopatológico, pois é necessária a exclusão de hipóteses de diagnósticos diferenciais associadas a outras doenças e, até mesmo, a possibilidade de associação com a Síndrome de Gorlin-Goltz.

\section{REFERÊNCIAS}

AMORIM, RFB, et. al. Ceratocisto odontogênico: estudo epidemiológico de $\mathbf{2 6}$ casos. Rev Odontol Ciênc. 2003;18(39): 23-30;

CHI, AC, OWINGS, JR, MULLER, S. Peripheral odontogenic keratocyst: report of two cases and review of the literature. Oral Surg Oral Med Oral Pathol Oral Radiol Endod. 2005;99(1):71-8;

FORSSEL, K., et. al. Recurance of keratocysts. A long-term follow-up study. Int J Oral Maxillofac Surg, v.17, n.1, p.25-28, 1988; 
FORSSEL, K. The primordial cyst. A clinical radiografic study. Proc Finn Dent Soc, v.76, n.3, p.129-174, 1980;

GUERRA, L., et al. Tratamento conservador de múltiplos tumores odontogênicos ceratocísticos em paciente não sindrômico. Rev. cir. traumatol. buco-maxilofac. [online]. 2013, vol.13, n.2, pp. 43-50. ISSN 1808-5210.

GREGORY, C. Cirurgia buco-dento-alveolar. São Paulo: Sarvier, 1996;

MARCUCCI M. Tratamento cirúrgico e terapêutico complementar dos queratocistos odontogênicos: revisão de literatura [Dissertação de Mestrado]. São Paulo: Faculdade de Odontologia USP; 2002;

NEVILLE BW, et. al. Patologia oral maxilofacial. Rio de Janeiro: Ed. Guanabara Koogan; 2004. p. 570-573;

PEIXOTO, R. F. et al. Tumor odontogênico ceratocístico: revisão dos achados atuais. Rev. cir. traumatol. buco-maxilo-fac.,Recife, v.9,n.3,p.21-28 jul.-Set 09;

SHEAR M. Cistos da região bucomaxilofacial - diagnóstico e tratamento. 3. ed. São Paulo: Ed. Santos; 1999;

VAROLI F.P. et al. Tumor odontogênico queratocístico: características intrínsecas e elucidação da nova nomenclatura do queratocisto odontogênico. J Health Sci Inst. 2010;28(1):80-3.

Enviado: Agosto, 2020.

Aprovado: Setembro, 2020. 